\title{
WebWatch
}

\begin{abstract}
$F A Q \& A$
Answering the question of "where are the frequently asked questions most frequently answered?" is Internet FAQ Archives, a self-described online education site that offers an enormously broad range of questions and pairs them all with answers. The topics covered are mind-boggling. There are 96 "popular" FAQ indexes covering everything from hedgehogs to the Bee Gees. A search engine directs visitors to an even larger group of FAQs. Are you curious about PCR? Over 50 different FAQ-related sites are listed. If you've got questions and are looking for answers, odds are you'll find them at the Internet FAQ archives.

[www.faqs.org/faqs]
\end{abstract}

\section{Great Expectorations}

Go to the newsstand (or better yet, grab your iPad) and try to find a newspaper that doesn't contain an article related to genetics or genomics. You'll have a hard time doing so. Compiling all of this fascinating information is "The Spittoon," a free blog with oodles of tidbits from the ever-expanding knowledge base of human genomics. Written by the people of 23andMe (a genotyping service that extracts genetic information from saliva), The Spittoon averages 2-3 wellresearched articles per week. Recent offerings include discussions of SNPs connecting immune system genes to rheumatoid arthritis, new genetic variants linked to the likelihood of developing Alzheimer's disease, and non-genetic factors in multiple sclerosis.

[http://spittoon.23andme.com]

\section{Good Crop/Bad Crop}

If you're looking for the right plant for your garden, home, or shop (or are hoping to avoid the wrong one) and you want to learn how to care for it, PlantCare.com is probably for you. In fact, if you're looking for any information related to plants, this site is a likely place to dig it up. The Plant Encyclopedia has data on thousands of plants, while the Plant Forum affords users an opportunity to connect with each other on matters of mutual interest. Looking to identify a plant? Bingo! Questions are readily answered online. Wondering about composting? A do-it-yourself guide leads

\section{Image Nations}

Although in the middle of a major cyber facelift, Steve Baskauf's popular Bioimages Web pages, hosted at Vanderbilt University, is loaded with beautiful "faces" that surely won't need any alteration. The site's $10,000+$ photos of plants and animals (over 1000 species in all) from the US and Canada compare favorably with any other nature photography pages on the Web. There are other notable features, as well, including an interactive map with hot links to climate zone information, each accompanied by vegetation-related pics and data relevant for that area. The best validation of Bioimages might be its number of visitors: there have been over 2.3 million since April 2004. If

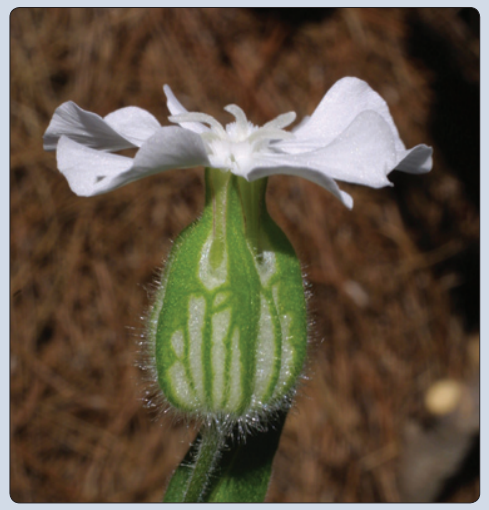

Sexual systems in angiosperms. Although female flowers are superficially similar to male flowers, stigmas project out of the corolla tube. (C) 2002 Steve Baskauf, Vanderbilt University. you're looking to learn about the organisms north of the Rio Grande, Bioimages should be on your radar.

[www.cas.vanderbilt.edu/bioimages/frame.htm]

you through it. Perhaps you're interested in exotics. PlantCare has these covered too. By the looks of things, the site's accolades from Time, USA Today, and The Wall Street Journal are all well deserved. [www.plantcare.com]

\section{The Pod Squad}

You've gotta hand it to the folks who put together Geek Pop; they're scientists and they're proud of it. Home to an online festival of science-inspired music, Geek Pop came onto the scene two years ago with its first virtual science music fest, Geek Pop '08, which featured some amusing and innovative performances by the Amateur Transplants ("The Anaesthetists Hymn"), Jonny Berliner ("Dark Matter"), and Tales from the Birdbath ("The Scientist"). Spanning all of science, Geek Pop's music is original and very clever. If you're a physicist, you'll have a hard time not chuckling at "Dark Matter," for example. Last year brought expansion, with free monthly podcasts available on iTunes. If you're looking for fun, creative, science-inspired artists, follow Geek Pop's advice: "Be there and be square."

[http://geekpop.podbean.com]

\section{Mirrored Perceptions}

$\mathrm{Oh}$, the difference a wee bit of stereochemistry makes! Consider limonene. It exists in two isomeric forms, R- limonene and S-limonene. The 'R' form has a fresh citrus, orange-like smell, whereas the ' $S$ ' form has a harsh turpentine-like smell with a hint of lemon. The only structural difference between the two molecules is the arrangement of four chemical groups around its single asymmetric carbon. Another, lilac alcohol, has eight stereoisomers arising from three different asymmetric carbons. Seven of them have fragrances described as sweet/flowery/ herbal, but one has no detectable odor at all. At the Chirality and Odour Perception site, you'll discover that these are only a tiny fraction of the hundreds of such stereoisomer pairs with differing fragrant properties.

[www.leffingwell.com/chirality/chirality.htm]

Written by Kevin Ahern, Ph.D. Please send web site recommendations to ahernk@orst. edu. 暞

BioTechniques 49:547 (August 2010)

doi 10.2144/000113460 